\title{
GEOGRAFIA E COVID-19: NEOLIBERALISMO, VULNERABILIDADES E LUTA
} PELA VIDA

\section{Geography and COVID-19: neoliberalism, vulnerabilities and the fight for life}

\author{
Júlia Adão Bernardes \\ Professora Permanente do Programa de Pós-Graduação em Geografia da UFRJ \\ julia.rlk@gmail.com \\ Roberta Carvalho Arruzzo \\ Professora Adjunta e Coordenadora do Curso de Licenciatura em Geografia da \\ Universidade Federal Rural do Rio de Janeiro \\ betarruzzo@hotmail.com \\ Daniel Macedo Lopes Vasques Monteiro \\ Doutorando pelo programa de Pós-Graduação em Geografia da UFRJ \\ danielmlvm@yahoo.com.br
}

Artigo enviado para publicação em 01/05/2020 e aceito em 03/05/2020

DOI: $10.12957 /$ tamoios.2020.50645

\section{Resumo}

No contexto do desenrolar da pandemia de Covid-19, que atinge diversos países do mundo, alguns aspectos das desigualdades socioespaciais se intensificam, resultando na emergência de questões que assolam os novos tempos e no agravamento de diversas vulnerabilidades sociais. Este artigo tem como objetivo trazer reflexões do campo da ciência geográfica, buscando oferecer uma contribuição da Geografia no que tange a uma análise crítica da sociedade e o debate das possibilidades cooperativas, em um mundo do capitalismo globalizado marcado por competitividades. $\mathrm{O}$ artigo se propõe a analisar as tendências atuais do neoliberalismo, as conseqüências das desigualdades territoriais na composição do Brasil, levando em consideração o contexto político atual, e as contribuições de uma Geografia que abarca o sentido da luta pela vida advinda da ajuda mútua entre as pessoas. Vale ressaltar que texto foi elaborado durante o período de isolamento social e num momento de aumento dos casos no Brasil, em que pensamos ser útil a exposição e a troca de ideias para a construção de uma Geografia marcada pela proliferação em escala global da Covid-19.

Palavras chaves: Covid-19; neoliberalismo; desigualdade social; vulnerabilidade social; cooperação.

\begin{abstract}
In the context of the development of the Covid-19 pandemic which affects several countries in the world, some aspects of socio-spacial inequality are intensifying, resulting in the emergence of issues that bring upon us new times and the worsening of various social vulnerabilities. This article offers reflections from geographic science, seeking to offer a contribution to a critical analysis of society and debate on cooperative possibilities, in a world of globalized capitalism marked by competitiveness. This study analyzes the current course of neoliberalism, the consequences of territorial inequalities in Brazil's structure, taking into account the current political context, and the contributions of a Geography that encompasses the meaning of the struggle for life coming from mutual aid between people. It is worth mentioning that the text was prepared during the period of social distancing and at a time of increasing cases in Brazil, in which we think it is useful to expose and exchange ideas for the construction of a Geography marked by the proliferation on a global scale of Covid-19
\end{abstract}

Key words: Covid-19; neoliberalism; social inequality; social vulnerability; cooperation. 


\section{Introdução}

Num mundo marcado por profundas diversidades e desigualdades de ordem econômica, política, social e cultural e em um contexto de confrontos políticos e ideológicos e de aprofundamento das rivalidades geopolíticas, da hegemonia do capital financeiro, das mudanças tecnológicas, de alterações nas divisões do trabalho e nas relações sociais (HARVEY, 2020), o modelo neoliberal vem sendo questionado. Harvey afirma que o mesmo se "assenta cada vez mais no capital fictício e numa vasta expansão na oferta do dinheiro e na criação da dívida", enfrentando a questão da insuficiente demanda "para realizar os valores que o capital é capaz de produzir" (2020 p.14), tendo como consequiência o aprofundamento do desenvolvimento geográfico desigual.

No âmbito desse modelo emerge a pandemia da Covid-19, a qual tende a assumir aspectos agravantes no caso brasileiro, quando se leva em conta o quadro econômico, político e social, significando profundas dificuldades para a sobrevivência. Acreditando que a ciência geográfica enquanto ciência social, cumpre papel relevante para a sociedade, nos propomos a trazer, neste artigo, breves reflexões sobre algumas dimensões da situação da população brasileira.

Num primeiro momento a reflexão estará centrada no papel do Estado e cidadania na sociedade brasileira no contexto neoliberal, tendo em vista os desafios colocados no momento atual; outro aspecto a ser abordado diz respeito às desigualdades e vulnerabilidades sociais, compreendendo como grupos - da periferia urbana, de indígenas e de quilombolas - estão passando por este momento sanitário no contexto político atual do país; por último, no âmbito da complexidade das relações entre sociedade e Estado, é fundamental a análise dos papeis exercidos por outras formas de organização social, das iniciativas populares e dos movimentos sociais na luta pela vida através da cooperação, em contraponto à competição que o sistema neoliberal tenta impor.

Este texto foi redigido em pleno isolamento social, ainda durante o crescimento dos casos de Covid-19 no Brasil, sem ainda termos nos deparado com o momento mais intenso desta crise no país. Buscamos aqui nos remeter às referências e dados que pensamos nos auxiliar na elaboração de um processo ainda em andamento e sem precedente na história de nossas vidas. São reflexões coletivas que pensamos ser útil compartilhar, enquanto giramos no olho do furacão que não sabemos onde irá nos levar.

\section{Geografia, Estado e cidadania no contexto neoliberal}

Dadas as características da atual fase capitalista neoliberal, em que o conhecimento do território tornou-se imprescindível, cabe à ciência geográfica um papel de destaque no sentido de contribuir no avanço do conhecimento. Assim, é importante enfatizar os nexos entre política e saber geográfico uma vez que a materialidade constitui o sustento e o resultado das relações sociais em geral e, em especial, das relações sociais de produção. Vivemos sob o comando de relações mundializadas, que se realizam no âmbito de possibilidades dos lugares, dos sistemas locais de recursos naturais, sociais ou econômicos, podendo resultar na criação de distorções e desigualdades (BERNARDES, 2011). Como afirmou Santos, 


\begin{abstract}
A Geografia alcança neste fim de século a sua era de ouro, porque a geograficidade se impõe como condição histórica, na medida em que nada considerado essencial hoje se faz no mundo que não seja a partir do conhecimento do que é o Território. O Território é o lugar em que desembocam todas as ações, todas as paixões, todos os poderes, todas as forças, todas as fraquezas, isto é, onde a história do homem plenamente se realiza a partir das manifestações da sua existência. A Geografia passa a ser aquela disciplina tornada mais capaz de mostrar os dramas do mundo, da nação, do lugar (SANTOS, 1999, p.7).
\end{abstract}

A seguinte questão constitui um aspecto importante para a elaboração deste item: em que medida uma ciência como a Geografia, que se fundamenta na dinâmica do território, pode oferecer sua contribuição na atual conjuntura da Covid-19? O ponto de partida para responder à questão proposta é a compreensão do contexto político e econômico que preside tais fatos, daí a importância de se recorrer à história.

No âmbito da crise de 1930 e do avanço do neoliberalismo, coube aos Estados capitalistas a implantação de grandes mudanças sociais. Milton Santos afirma que "nessas sociedades corporativas domina a propaganda, o consumismo, a cultura de massas e a burocracia como instrumento e fonte de alienação", aprofundando-se tal situação nos países menos desenvolvidos, onde se acentua o contraste entre "os que são mais cidadãos e os que são menos" (SANTOS, 1987, p.9). Acrescenta que no Brasil temos "uma cidadania mutilada, subalternizada", onde até os direitos básicos à educação e à saúde são pouco atendidos, situando-se a enormes distâncias do que normalmente encontramos em expressiva parte dos países capitalistas. Esclarece que a cidadania mutilada no Brasil se encontra no trabalho, desde a falta de oportunidades até a remuneração, na localização da moradia, na circulação, na educação, na saúde, especialmente devido à elitização da medicina, no acesso à evolução técnica, em suma, no livre exercício da individualidade. Para o geógrafo,

Ser cidadão é ser um indivíduo dotado de direitos que lhe permitem não só se defrontar com o Estado, mas afrontar o Estado. O cidadão seria tão forte quanto o Estado. O indivíduo completo é aquele que tem a capacidade de entender o mundo, a sua situação no mundo e que, se ainda não é cidadão, sabe o que poderiam ser seus direitos. (SANTOS, 1996, p.133).

Ao relacionar cidadania com classes sociais, o autor assegura que a definição de classes sociais exige a consideração da base territorial, ou seja, das condições específicas de cada lugar na medida em que "os cidadãos não têm o mesmo peso nem usufruto em função do lugar em que se encontram” (SANTOS, 1987, p.82). Portanto, nesse contexto neoliberal de imposição da informação e do dinheiro, em que a produção da materialidade e a existência das pessoas é profundamente afetada, em que tudo se desregula e desorganiza, em que cada fração do território muda rapidamente (SANTOS, 1991), a pandemia da Covid-19, na visão de Sousa Santos, "vem apenas agravar uma situação de crise a que a população mundial tem vindo a ser sujeita" (2020, p.2), e a crise financeira permanente, os cortes que vêm ocorrendo na educação, saúde, previdência social e na degradação dos salários, fazendo com que o território se torne praticamente ingovernável em suas várias dimensões: nacional, estadual e municipal.

As Pastorais Sociais do Campo (2020) também denunciam que a crise que hoje enfrentamos é reveladora da falência do atual modelo civilizatório, afirmando que a 
privatização e a mercantilização do território dos camponeses, povos originários e demais povos e comunidades tradicionais, além de comprometer a vida e os modos de vida sustentáveis dessas populações, também afetam a alimentação da população brasileira, os ecossistemas, a qualidade da água e do ar, do clima e da saúde, provocando a desterritorialização forçada dessa população, alimentando o trabalho escravo e a eliminação de suas lideranças.

Vale a pena registrar a fala do pesquisador José de Souza Martins, que muito sabiamente declara: "A epidemia é imprevisível. Economia que subestima as carências da sociedade, não". O contexto de exclusão social decorrente da economia e da política que vem dominando o país, difundindo a pobreza e a exclusão social constitui terreno fértil para as doenças. E assim, as condições sociais estão preparadas para a Covid-19 se instalar. Tais condições são consequência da política econômica de Estado mínimo que vem se desenvolvendo desde1964 neste país (MARTINS, 2020, online).

Segundo o economista José Luís Fiori, a importância do papel do Estado neste momento consiste no "desenvolvimento de uma política keynesiana mais profunda". Não obstante, o despreparo e a falta de comando no âmbito político, tornam-se um agravante no caso brasileiro, resultando na agudização da crise da saúde, não conseguindo o governo desenvolver um plano econômico, ou seja, "emitir e distribuir o dinheiro indispensável para que as pessoas - sobretudo os desempregados e subempregados", possam subsistir nesta fase da crise. Fiori nos alerta que, quando a epidemia alcançar com maior intensidade as populações mais pobres, desempregadas e marginalizadas desse imenso país, que apresenta enormes desigualdades sociais, os resultados serão devastadores, podendo a situação se agravar "quando começarem a surgir focos de rebeldia social inorgânica, movidos pela fome e pela miséria" (FIORI, 2020, online).

Milton Santos (1999, p.13) nos diz que "um outro dado que resiste a essa ação cega do dinheiro é a cidadania", mas complementa que "jamais tivemos cidadãos" no Brasil. Contudo, se os direitos fossem reconhecidos e respeitados neste país, certamente tal fato constituiria valiosa contribuição na atual situação de enfrentamento dos desafios da Covid-19, e não sério agravamento da crise que vivenciamos, a qual rapidamente se instala e propaga, agravando o funcionamento de setores fundamentais como a saúde, a qual, de fato, nunca funcionou adequadamente para a maioria da população, embora o país conte com um sistema público de saúde (SUS), ainda que bastante precário.

Por outro lado, no caso brasileiro, são numerosas as áreas e grupos sociais que o sociólogo Sousa Santos (2020) denomina de "zonas de invisibilidade" (p.9), como as favelas, as aglomerações periféricas, os grupos indígenas, os quilombolas, os agricultores familiares, os assentados, e ainda o numeroso grupo dos moradores de rua, que constituem os setores mais atingidos por essa precariedade, ou seja, o "Brasil invisível". Essa invisibilidade, segundo o autor, "decorre de um sentido comum inculcado nos seres humanos pela educação e pela doutrinação permanentes” (p.12).

Considerando que o que é produzido é desigualmente distribuído, Santos define "as duas naturezas da escassez, a dos possuidores, os ricos e a classe média, e a dos excluídos, os pobres. Complementando a afirmação do sociólogo Max Weber, de que "quando o processo de expansão da racionalidade capitalista se tornar ilimitado, quem sabe estaremos em medida de voltar ao reino da razão", o geógrafo enfatiza que "a volta à razão é materializada na explosão de contra-racionalidades, racionalidades paralelas e não irracionalidades, que foram jogadas embaixo do tapete da história" (SANTOS, 
1997, p.1). Em suma, as contra-racionalidades, referidas pelo autor, estão articuladas com o território, significando que o mesmo também pode ser definido nas suas desigualdades, uma vez que a distribuição do dinheiro e dos recursos não se dá da mesma maneira, sustentado por distintas formas de infraestrutura, por certo sistema ideológico, no âmbito de determinadas condições técnicas e políticas (SANTOS, 1999).

\section{Estamos todos no mesmo barco? As desigualdades e vulnerabilidades sociais brasileiras em tempos de pandemia}

No contexto do quadro abordado acima no que se refere à atuação do Estado e à cidadania, há aqueles que dizem que a pandemia do Covid-19 é democrática, visto que abarca pobres e ricos, negros e brancos, homens e mulheres. Com isso, o bordão abrangente soa nos quatros cantos do mundo: "estamos todos no mesmo barco". Mas de fato, a dispersão dos casos e o número dos óbitos ocorrem por todo território de maneira homogênea?

O mar do vírus pode até ser o mesmo, mas não enfrentaremos a tempestade na grande arca de Noé. Há barcos diferentes. Poucos estão se abrigando nos iates, alguns em barcas e saveiros, outros em pequenas canoas ou até mesmo em pequenos pedaços de madeira, além daqueles que nada têm para enfrentar o grande maremoto que se aproxima. Esses têm apenas seus próprios braços para nadar nessa tempestade, "furando" onda por onda, dia após dia. Neste sentido, buscaremos a seguir abordar mais detalhadamente as desigualdades, que resultam em intensas vulnerabilidades, no contexto brasileiro.

As geografias das desigualdades: quando a pandemia da Covid-19 reflete impiedosamente os processos históricos passados

As geografias desiguais escancaram as entranhas do país e o divide entre, por exemplo, os que têm e os que não têm sabão. Quando o básico como água não é um direito de todos, a sociedade torna-se um barril de pólvora prestes a estourar.

A formação espacial brasileira é oriunda do produto histórico das relações sociais no país. Assim, ao analisar esta sociedade, é importante considerar a construção do território-nação e seus fluxos internos e externos, sejam eles econômicos ou culturais. Nesta análise trazemos como pano de fundo dois elementos resumidamente elencados por Souza (1994) das profundas raízes históricas que reverberam e são externalizadas até hoje em nossa sociedade.

1. O Estatuto da Escravidão (século XIX) e sua longa permanência, aliado ao processo histórico de formação da nossa estrutura agrária, que torna, por exemplo, inadmissível a extemporânea discussão da monarquia ao Brasil.

2. Os padrões sócio-político-institucionais herdados de Portugal e preservados no Brasil "independente"

Este é sem dúvida o grande país dos paradoxos. (SOUZA, 1994, p,26)

Sem dúvida, o Brasil assume como fato suas verdades controversas. Segundo o Fundo Monetário Internacional (2019) somos a nona economia do mundo, porém como Souza (1994) afirma, passamos de um enorme cafezal para uma das maiores economias do mundo, isto às custas de um sistema de má distribuição de renda, construindo assim 
os abismos entre a riqueza gerada e a pobreza, até hoje existentes, materializadas na fome, no analfabetismo, nas epidemias e na violência.

Segundo a Síntese de Indicadores Sociais (SIS-IBGE, 2019), no Brasil a extrema pobreza atinge 13,5 milhões de pessoas, equivalente a populações de países como a Bélgica ou a Bolívia, são pessoas que vivem com menos de R \$145,00 por mês. Quando considerado o parâmetro do Banco Mundial, o rendimento seria de US\$ 5,50 por dia, o que daria um total de 52,5 milhões de brasileiros. Isso significa aproximadamente um quarto da população vivendo abaixo da linha da pobreza. Quando comparado com outros países, equivale a um número maior do que a população total da Coréia do Sul, da Espanha ou da Argentina.

Do outro lado da balança o Brasil registrou, segundo dados da Pesquisa Nacional por Amostra de Domicílio Contínua (PNAD Contínua/IBGE, 2018), que 1\% da população mais rica concentra uma renda 34 vezes maior que a metade da população mais pobre. Isto significa que a parcela mais rica arrecadou neste ano em média $\mathrm{R} \$$ 27.744,00 por mês, enquanto metade da população brasileira tem renda média mensal de $\mathrm{R} \$ 820,00$. Essa disparidade entre as classes sociais no Brasil é produto do seu processo histórico, em uma sociedade constituída por privilégios, e não por direitos.

A chegada da pandemia da Covid-19 revela, mais do que nunca, as feridas expostas da sociedade brasileira, ao mesmo tempo em que apresenta como de extrema urgência a garantia básica de direitos mínimos para uma grande parcela da população. Água encanada, sabão e água sanitária para enfrentar o vírus são itens tão banais, no entanto em 2020 muitas pessoas não possuem acesso a esses recursos. Em um país das "cidadanias mutiladas" combater o vírus da maneira mais simples traz à tona o básico negado a grande parte da população por séculos.

Josué de Castro (1984), ao discorrer sobre a questão da fome, deixava evidente que o progresso do mundo poderia estar comprometido por causa da fome e da revolta dos famintos. Em seu clássico Geografia da Fome, lançado em 1946, o autor alerta que o desenvolvimento de um país e do progresso social não pode ocorrer de uma maneira desigualmente distribuída. $\mathrm{O}$ autor alerta para que o Governo, a partir do desenvolvimento econômico, esteja mais atento às necessidades dos grupos humanos, caso contrário o "gigante brasileiro" pode vir a "crescer capenga ou torto" (CASTRO, 1984, p. 297).

Castro (1984) afirmava que a emancipação econômica do país deveria se atentar para a melhor distribuição da renda, pois para ele as "cotas de sacrifício" pesavam quase que exclusivamente para as classes menos favorecidas, na qual eram consumidas em face do avassalador aumento do custo de vida. Após 74 anos do lançamento do livro, observamos que a estrutura geral de desenvolvimento econômico do país continuou pautando as "cotas de sacrifício" aos mesmos indivíduos de outrora.

No cenário de agravamento das desigualdades sociais e territoriais, a Geografia da Fome de Castro alerta que o desenvolvimento econômico e social dá grandes saltos na história, contudo é necessário evitar que "seja um salto no abismo, orientando-o de forma que as nossas forças nos permitam alcançar o outro lado do fosso a ser ultrapassado" (CASTRO, 1984, p.297). A pandemia atual é um recorte do tempo presente que, para ser enfrentada deve, concomitantemente, nos alertar para as estruturas retrógradas, reacionárias, tradicionalistas e rígidas da sociedade brasileira. Contudo, para alcançarmos o outro lado do fosso pós-pandemia, é necessário resgatar Josué de Castro que destaca perfeitamente que "não é possível saltar esse fosso com um 
povo faminto, um povo que não disponha do mínimo essencial para suas necessidades básicas de vida, um mínimo essencial de alimentação" (CASTRO, 1984, p.298).

O abismo atual a ser atravessado é a pandemia da Covid-19 em um território constituído por movimentos desiguais, com explorações do trabalho e da natureza até a exaustão, território marcado por conflitos de diversas ordens o que desperta para compreender a Geografia da disseminação.

Se do Príncipe de Mônaco ao funcionário de operações do metrô de São Paulo - passando por senadores, generais, professores, empregadas domésticas - todos possam sofrer com a contaminação do vírus, é preciso reparar as condições de atenção, proteção e cuidados aos homens e mulheres mais vulneráveis, não só por conta da idade ou de um histórico de saúde, mas sim de sua condição social de corpo e território. (BARBOSA, p.2, 2020)

Josué de Castro ressurge na provocação feita pelo autor. Como um corpo faminto e um território desigual e em conflito atravessam uma das maiores crises sanitárias e econômicas da história?

A fábula das máscaras, das luvas e do álcool em gel para todos VS a realidade dos centros urbanos brasileiros

Damos o nosso coração, alegria e amor a todos sem distinção de cor

Mas depois da ilusão, coitado Negro volta ao humilde barracão

Negro acorda é hora de acordar

Não negue a raça

Torne toda manhã dia de graça

$(\text { CANDEIA })^{2}$

Candeia na canção versa a alegria democrática do carnaval. Segundo ele, o carnaval abraça a todos, sem nenhuma distinção. No entanto, depois da festa o negro, trabalhador, morador do humilde barracão acorda e precisa ir para a labuta novamente ganhar seu pão de cada dia.

Ao fazer uma analogia com o contexto atual, temos a pandemia como o inverso da alegria contagiante do carnaval. Ela chegará para todos, porém no dia seguinte uns precisarão sair de seus humildes barracões para sobreviver, enquanto outros, farão uso do álcool $70^{\circ}$ nas suas residências em home office. Mas se não há movimentação econômica nas ruas, como a próxima manhã se tornará "dia de graça"? As desigualdades no Brasil explodem todo momento na nossa história, seja nas alegrias das aglomerações do carnaval, seja no isolamento social da pandemia de coronavírus.

Novamente retomamos Milton Santos (2008), quando nos trouxe a discussão dos circuitos da economia em países como o Brasil. Aqui o espaço urbano é dividido. Contudo, aqueles que trabalham diretamente com o circuito inferior e dele extraem sua sobrevivência, estão diretamente afetados com a paralisação econômica. Apesar da correlação existente entre os dois circuitos, há uma subordinação do circuito inferior por parte do circuito superior, no que tange ao controle da economia. Uma vez estagnado o superior, as pessoas que vivem de modo autônomo e/ou em trabalhos informais são as primeiras a serem diretamente prejudicadas com a paralisação da economia. 
Esses trabalhadores dos centros urbanos que tiveram sua renda diária interrompida, como os que continuam a trabalhar em serviços essenciais - como mercados, farmácias, condutores de transportes públicos, entregadores de comida por aplicativos (...) - residem em áreas precárias de habitação e infraestrutura de serviços básicos. Como resolver o problema estrutural de décadas para diminuir o contágio nessas localidades? No entanto, no contexto neoliberal que vimos no tópico anterior, não parece haver urgência do Estado para garantir o mínimo para a sobrevivência e proteção dessas pessoas, como já citado anteriormente por Josué de Castro: não saltamos abismos com uma população faminta.

Destaca-se, também, a composição racial dos vulneráveis pela Covid-19 no Brasil. Os moradores de favelas e periferias, assim como os que estão em situação de rua são expressivamente compostos por pessoas negras (Campos, 2011). Os traços da desigualdade no país têm corpo e território. A ilustração mais evidente deste cenário, por mais figurado que pareça ser, foi o caso da primeira morte notificada por Covid-19 no estado do Rio de Janeiro, uma empregada doméstica, moradora de Miguel Pereira, periferia da metrópole, que contraiu o vírus de sua empregadora que voltara da Itália e residia no Leblon. Nada mais revelador que em um dos espectros urbanos mais recortados pela desigualdade no país, o primeiro óbito tenha tal configuração.

Dentre os grupos de risco de pessoas que envolvem a Covid-19 estão as pessoas com comorbidades especificas. Questões históricas, sociais, econômicas e políticas desenham estruturas da sociedade e, consequentemente, a prevalência de certas doenças ligadas à cor/raça e classe. Segundo a Associação Brasileira de Saúde Coletiva (Abrasco, 2020), no Brasil, a população negra registra números maiores de casos associados a comorbidades, como diabetes e hipertensão, além da anemia falciforme, oriunda das pessoas escravizadas no passado, advindas da África.

A pandemia não revela somente as desigualdades sociais, mas também o racismo estrutural e cotidiano da sociedade brasileira. A privação dos direitos está associada ao modo de viver. É importante destacar que essa população não se encontra somente em estado de vulnerabilidade pela Covid-19, mas também com outras doenças que assolam as periferias, como a tuberculose e a dengue. Com um sistema de saúde sobrecarregado com as vítimas da pandemia, o tratamento para as demais doenças que nos cercam se torna ainda mais precarizado.

De acordo com Santos (2000) os territórios diversos gerados pelos processos de globalização e de fragmentação fazem emergir uma dupla tirania: a do dinheiro e a da informação. Quando o grupo tratado é a população em situação de rua, essa dupla tirania age com força em cima da invisibilidade dessas pessoas para a sociedade. Se todos devemos usar as máscaras num período de no máximo 2 horas e depois retirá-las e higienizá-las, como isso ocorre com as pessoas que estão em situação de rua? O desafio se torna ainda maior quando envolve esse grupo. Se dentre a maior parte da população em situação de rua, residente de favelas, cortiços, trabalhadores de serviços essenciais, logo, utilizadores de transportes públicos são negros, há de se ter uma política específica para essa população enfrentar a pandemia. É necessário racializar o debate a ser feito, pois os dados podem camuflar o racismo cotidiano.

É fundamental o alerta para que as desigualdades não se acentuem durante e após a pandemia. Nesse sentido, mostram-se relevantes as discussões/reflexões realizadas durante o desenvolvimento do GT Racismo e Saúde da Abrasco, nas quais foram elencados 12 pontos importantes para a redução dos impactos negativos da 
Covid-19 em grupos vulnerabilizados, como forma de enfrentar o contágio e as consequências em série ${ }^{3}$. Os pontos reafirmam políticas que deveriam ser constantes, mas que foram negligenciadas ao longo do tempo, por isso a necessidade da construção de estratégicas em conjunto com a população.

Quando o vírus político pode ser o maior desafio nos tempos de pandemia: a dupla luta pela sobrevivência dos indígenas e quilombolas

Para compreender a situação atual dos povos indígenas e quilombolas diante da pandemia, é importante contextualizar o momento político brasileiro. O Brasil é presidido por um governo de extrema direita, eleito com uma bandeira neoliberal na economia e conservadora nos costumes, opondo-se a diversos setores da sociedade. Um discurso construído através da segurança da propriedade privada e da moral judaicocristã. Ficam evidente nas falas de seus membros os ataques às políticas e ao direito constituído dos povos tradicionais, como indígenas e quilombolas

Para esses povos a luta contra o coronavírus é intensificada, voltada para a defesa de seus territórios e a manutenção de seus direitos. Nesse contexto de pandemia, o governo brasileiro publicou uma resolução $\mathrm{n}^{\circ} 11$ do Diário Oficial ${ }^{4}$ do dia 26 de março de 2020, na qual autoriza a remoção e o reassentamento de quilombolas que vivem próximos à base da aeronáutica do Centro de Lançamento de Alcântara no estado do Maranhão. Esta ação não teve data estabelecida para ser executada. O objetivo do governo é expandir a base, fruto de um convênio do governo brasileiro com o governo dos Estados Unidos. Essa expulsão engloba 800 famílias que vivem na área desde o século XVII. Uma expulsão anunciada no momento em que a recomendação da Organização Mundial da Saúde é de nos mantermos em casa e em isolamento social.

Compreender as articulações estratégicas entre as escalas revelam as disputas sobre o território. Para Santos (1996) a noção de escala quando aplicada aos eventos parte de duas interpretações: a escala da origem e a escala do impacto. A escala, neste caso, é compreendida como forças operantes, levando em conta a área de influência e as dimensões territoriais. Essa análise faz compreender a decisão geopolítica originada pelos Estados Unidos em uma escala que ultrapassa a escala interplanetária - afinal de contas, o interesse justificado por eles pela Base de Alcântara, diz respeito ao lançamento de satélites - terá sua escala de impacto na comunidade quilombola de Alcântara no Maranhão. Neste contexto, as prerrogativas do conflito de mundos distintos se materializam no território no momento atual de pandemia. O momento escolhido pelo governo de Jair Bolsonaro para emitir a resolução causa uma dupla vulnerabilidade do grupo em questão: a perda de seu território e a ameaça da contaminação pelo coronavírus.

Os povos indígenas encontram-se em situação semelhante. Marcados pela história do contato com os brancos, os grupos indígenas perpetuaram o extermínio de parte de seu povo através de doenças que no passado foram utilizadas como arma biológica. Exemplificaremos aqui dois casos que intensificam a luta pelos seus territórios e por garantir seus modos de vida, que se tornaram duplamente vulneráveis em tempos de pandemia.

Práticas evangelizadoras ameaçam a vida dos povos originários desde a chegada dos europeus no continente. O primeiro caso revela que essas práticas não foram interrompidas nem em tempos de quarentena e isolamento social. Atualmente, o grupo 
Missão Novas Tribos do Brasil $^{5}$ quer, no século XXI, aproveitar a situação global de pandemia para manter o contato com povos indígenas em isolamento voluntário e recém contatados. A missão desses evangelizadores é entrar em contato com povos no Vale do Javari no estado do Amazonas, um dos locais com maior número de povos indígenas isolados ${ }^{6}$.

A organização indígena União dos Povos do Vale do Javari (UNIVAJA) denunciou ameaças advindas desse grupo de missionários para conseguir a autorização para adentrar as Terras Indígenas. O Ministério Público, em decisão histórica, proibiu judicialmente a entrada desses grupos religiosos na localidade. A ameaça de evangelização permeia uma discussão ideológica de certos grupos em levar a palavra de Cristo para todos os povos do planeta. Além da violência simbólica, em importunar o contato com grupos que decidiram, por conta própria, se manterem isolados, há o perigo iminente de transferir doenças como a Covid-19 para esses grupos com pouca imunidade biológica.

A ameaça por parte dos garimpos, exemplifica uma segunda linha de disputa territorial e proteção das áreas indígenas. Segundo dados do Instituto Nacional de Pesquisas Espaciais (INPE), houve um aumento de 29,9\% no número de alertas de desmatamentos na Amazônia em março de 2020, quando comparado com março de 2019. O Instituto Brasileiro do Meio Ambiente e dos Recursos Naturais Renováveis (IBAMA) atuou no combate as áreas invadidas no Pará para prevenir que povos indígenas tenham seus territórios devastados pelo garimpo e madeireiras, evitando também uma possível contaminação pela Covid-19 nas suas aldeias.

Em contrapartida o Ministro do Meio Ambiente, Ricardo Sales, demitiu o diretor do IBAMA responsável pela operação. Essa demissão ocorre no andamento do movimento que tinha como estratégia elementar, proteger as áreas indígenas e os povos que nelas habitam, evitando a proliferação do vírus da Covid-19 nessas comunidades. A demissão está sendo investigada pelo Ministério Público ${ }^{7}$.

As atividades de mineração, junto com o agronegócio, são dois setores da economia que têm tido forte participação nas ameaças ao direito dos indígenas a seus territórios. Além disso, agentes desses setores no governo atual incentivam através de seus discursos tais práticas. Um exemplo, é o projeto de lei $191 / 2020^{8}$ assinado pelo presidente da república, que autoriza a utilização das Terras Indígenas para os usos de mineração e aproveitamento dos recursos hídricos para a geração de energia.

Para certos grupos sociais, lutar contra a Covid-19 vai além de higienizar as mãos e manter o isolamento social. Sônia Bone Guajajara, na live promovida pela Articulação dos Povos Indígenas do Brasil (APIB), no dia 26 de março de $2020^{9}$, afirma que

é um risco morrer pelo coronavírus, mas ao mesmo tempo é um risco morrer por essas políticas adotadas pelo próprio governo, autorizar mineração nas Terras Indígenas, não combater o desmatamento, ficar insultando cada vez mais e promovendo o que há de pior no ser humano, que é exatamente essas práticas de racismo que tem se acentuado, esses ataques e todo esse ódio que as pessoas têm agora destilado contra os povos indígenas, para nós é um cenário de guerra, como se cada um de nós estivesse procurando um refúgio seguro.

Sônia Guajajara, nesta fala, ressalta a vulnerabilidade também dos direitos. No entanto, os órgãos do Estado, responsáveis pela questão indígena e quilombola, 
apresentaram certa demora a agir para promover a defesa e o auxílio a esses povos diante do estado de calamidade pública, tendo em vista que o primeiro caso registrado no país ocorreu no dia 26 de fevereiro de 2020. Neste sentido, realizamos um levantamento nas notícias divulgadas nos sites oficiais da Fundação Nacional do Índio (Funai) - responsável pelas políticas para os povos indígenas - e da Fundação Cultural Palmares (FCP) - responsável pelas políticas para as comunidades quilombolas - com a finalidade de datar as primeiras iniciativas das duas entidades no que tange à proteção e às políticas públicas dos indígenas e quilombolas.

De acordo com as notícias publicadas pelo site da Funai, a primeira publicação é datada do dia 13 de março de 2020 sobre o tema. O comunicado relatava a solicitação do órgão para utilizar a Força Nacional no prédio em que a Funai é sediada, a fim de coibir possíveis aglomerações de indígenas que ali fossem se manifestar. A autorização foi permitida pelo Ministério da Justiça e Segurança Pública, através da Portaria $n^{\circ} 111$, de 11 de março de $2020^{10}$. Dessa forma, a primeira medida do órgão foi utilizar o aparato de repressão estatal, usando a prevenção da proliferação do vírus como justificativa.

No entanto, a primeira medida de fato notificada em relação à proteção dos povos indígenas ocorreu no dia 18 de março de 2020, na qual o órgão suspende autorizações de entradas em Terras Indígenas, com exceção das ações dos serviços essenciais, devido à pandemia, por meio da Portaria $n^{\circ} 419$, de 17 de março de 2020, suspendendo também atividades de contato com grupos indígenas isolados ${ }^{11}$. Essa medida ocorreu 21 dias depois do primeiro registro da doença no Brasil. Nesta data, segundo o Ministério da Saúde, o país já registrava 408 casos da doença em 21 unidades da federação, além do registro da primeira morte.

No que diz respeito à FCP a primeira notícia sobre o tema é datada de 23 de março de 2020, porém, somente aponta que o atendimento do órgão seria feito de forma remota devido ao controle da Covid-19. No final da notícia há um parágrafo reforçando as recomendações relacionados aos cuidados coletivos e individuais ${ }^{12}$.

Todavia, a primeira medida notificada pela fundação ocorreu somente no dia 06 de abril de 2020, na qual o órgão articulou algumas iniciativas para a proteção dos quilombolas, anunciando intensificar as ações com o Ministério da Saúde e com a Companhia Nacional de Abastecimento (Conab). A notícia também relata a solicitação feita ao Ministério da Saúde para a distribuição de materiais de higiene, a disponibilização de agentes de saúde para os quilombos, além da cartilha virtual "Não Leve a COVID-19 Pro Quilombo"13. Essa notificação ocorreu 40 dias depois do primeiro caso registrado no Brasil. Nesta data, segundo o Ministério da Saúde, o país já registrava 12.056 casos e 553 óbitos, em 26 unidades da federação.

Os dois órgãos oficiais se mostraram letárgicos diante da gravidade da situação, principalmente tratando-se de grupos sociais de extrema vulnerabilidade. Torna-se necessário que a gestão pública, em todas as suas esferas de atuação, amplie e fomente políticas públicas que possam minimizar os impactos causados pela Covid-19. Assim sendo, Sônia Guajajara propõe seis pontos para que políticas públicas possam ser reforçadas com a finalidade de enfrentar essa situação.

1 - A Sesai precisa adotar imediatamente o critério de contágio comunitário; 2 - A SESAI precisa disponibilizar Testes rápidos em quantidade suficientes para testagem dos indígenas. Se não houver esse acesso não teremos como 
saber o número exato de contaminação e assim facilitar ainda mais a propagação do vírus nas aldeias;

3 - A SESAI precisa atender de forma igualitária todos os indígenas, independente de onde vivam;

4 - A construção de Hospitais de campanha e para atendimento exclusivo dos povos indígenas na Amazônia;

5 - A FUNAI precisa investir os 11 milhões de reais no combate ao coronavírus;

6 - Retirada imediata de todos os invasores madeireiros e garimpeiros dos Territórios Indígenas"14

Esses pontos sugeridos para o enfrentamento junto com as causas indígenas, também são relevantes no fortalecimento da luta quilombola. Setores da sociedade brasileira legitimam o caráter de negação de direitos e a prerrogativa etnocida em certas políticas implementadas. $\mathrm{O}$ combate à pandemia para esses povos reforça ainda mais a luta pelos seus territórios. O reconhecimento e defesa das terras indígenas e quilombolas é uma questão de existência, é o reconhecimento de seus territórios.

É evidente a importância da gestão da saúde, da atuação da economia, dos investimentos em inovações tecnológicas para combater os prejuízos causados pela pandemia, no entanto se faz necessária a compreensão e a valorização da geografia, assim como das demais áreas das Ciências Humanas. A resposta sanitária no que diz respeito ao planejamento indica e mapeia as ações que devem ser aplicadas no território. Os dados estatísticos que são gerados com a atualização dos números dos contágios e dos óbitos, têm corpo e território! Compreender "quem" e "onde" estão os focos, precisa caminhar junto com o "como fazer" para amenizar a disseminação, de acordo com as especificidades de cada grupo social.

\section{Apoio mútuo, luta pela vida e os sentidos das ações}

A palavra e o ouvido, com o coração, tem muitos caminhos, muitas maneiras, muitos calendários e muitas geografias a encontrar. E essa luta pela vida pode ser uma delas ${ }^{15}$.

As palavras zapatistas escolhidas como epígrafe deste momento do texto finalizam um comunicado publicado em março de 2020, recomendando o encerramento temporário de diversas formas de encontros e recomendações de cuidados de saúde e higiene. A proteção e a luta pela vida aparecem no centro de diversas ações de indígenas, camponeses, movimentos sociais e dos mais diversos sujeitos que aqui entendemos como vulneráveis e periféricos. À ameaça de doença, morte e aprofundamento da pobreza e miséria, diversos grupos populares respondem com ações de solidariedade, auto-organização e cuidado coletivo. Pensamos que a Geografia e seus diálogos também podem ter algo a dizer sobre estas relações.

A Geografia, em especial no século XIX e parte do XX, foi fortemente influenciada por ideias evolucionistas, sejam elas ligadas a correntes darwinistas ou neo-lamarckistas (Ribeiro, 1999) em que pesavam debates e divergências a respeito dos mecanismos de luta pela vida que levavam às mudanças nas espécies. Um dos importantes nomes da história da Geografia, o anarquista Piotr Kropotkin, publicou em 1902 um livro intitulado "Ajuda Mútua: um fator de evolução". Nesta publicação, o autor se concentrou em demonstrar, se contrapondo em grande parte ao darwinismo 
social presente em sua época nas Ciências Sociais (incluindo a Geografia), como a ajuda e o apoio mútuo são importantes fatores para o fortalecimento de uma espécie.

Kropotkin chama a atenção para o fato de que, mesmo na natureza, há uma diferença razoável dos mecanismos de luta pela vida intra e entre espécies. O fator competição aparece como menos determinante dentro de diversas espécies. Segundo ele, ao observar animais em áreas de escassez de recursos,

\begin{abstract}
naqueles poucos lugares onde a vida animal prolifera em abundância, não consegui descobrir, embora estivesse procurando atentamente, aquela luta cruel pelos meios de subsistência entre animais que pertencem à mesma espécie, considerada pela maioria dos darwinistas (embora nem sempre pelo próprio Darwin) a característica dominante da luta pela sobrevivência e o principal fator da evolução (KROPOTKIN, 2009, p.11).
\end{abstract}

O autor passa então a duvidar sistematicamente, elaborando capítulos que englobam desde a vida animal até a vida humana em diferentes momentos históricos, de que a competição por recursos e alimentos dentro de uma mesma espécie seja um mecanismo tão eficiente de evolução quanto pareceria para muitos outros autores. Para Kropotkin, a ajuda e apoio mútuo parecem muito mais comuns e relevantes nas relações intra espécie do que períodos de intensa competição interna. Assim,

\begin{abstract}
mais tarde, quando as relações entre o darwinismo e a sociologia me chamaram a atenção, não pude concordar com nenhuma das obras e panfletos escritos sobre esse tema tão importante. Todos eles tentavam provar que os seres humanos, devido à superioridade de sua inteligência e de seus conhecimentos, podiam mitigar entre si a dureza da luta pela vida. Mas, ao mesmo tempo, todos eles concordavam que a luta pelos meios de subsistência, a luta de todo animal contra seus semelhantes, e de cada ser humano contra todos os outros, era uma "lei da Natureza". Eu não podia aceitar esse ponto de vista, porque estava convencido de que admitir uma implacável guerra interna pela vida no seio de cada espécie - e ver nessa guerra uma condição de progresso - era admitir algo que não só não havia ainda sido provado, como também não fora confirmado pela observação direta. (KROPOTKIN, 2009, p.12).
\end{abstract}

A proposta de enfatizar que a luta pela vida não se dá apenas através da competição mas também, e em grande parte, por relações de cooperação, coletividade e ajuda mútua acabou por ter pouca influência no pensamento geográfico, apresentando uma pequena tendência de ressurgimento nas últimas décadas do século $\mathrm{XX}$ (Soubeyran, 1984). Embora relacionado a outras influências teóricas, críticas à ênfase no imperativo da competitividade e à sua real importância na vida cotidiana de homens (e mulheres) "lentos" também estão presentes na obra de Milton Santos. Acreditamos ser interessante este diálogo anacrônico e eclético, como uma tentativa de expansão dos entendimentos e propostas da Geografia para pensarmos as relações entre cooperação e competição na luta pela vida.

Para Santos (1996) as palavras que permeiam a ordem do dia são a fluidez e competitividade. Enquanto a fluidez é a condição para os espaços da racionalidade, é a competitividade que guia estas ações, que o autor nomeia de ações hegemônicas. Como nos aponta o autor,

A busca da competitividade, tal como apresentada por seus defensoresgovernantes, homens de negócio, funcionários internacionais- parece bastar- 
se a si mesma, não necessita de qualquer justificativa ética, como, aliás, qualquer outra forma de violência. A competitividade é um outro nome para a guerra, desta vez uma guerra planetária, conduzida, na prática, pelas multinacionais, as chancelarias, a burocracia internacional, e com o apoio, às vezes ostensivo, de intelectuais dentro e fora da Universidade (SANTOS, 1996, p. 35).

Enquanto a fluidez, calcada na competitividade sem sentido ético, é um componente central na organização dos espaços da racionalidade dominante, nomeados por Santos como espaços "luminosos", coexistem também os espaços das contraracionalidades e os espaços opacos. Neste ponto chamamos para o diálogo a socióloga Ana Clara Torres Ribeiro. Ribeiro (2011), baseada nas propostas de Max Weber, que nos chama a atenção para a importância de compreendermos os sentidos das ações. Santos nos aponta que o agir social dominante se baseia "numa racionalidade sem outra razão que a do lucro, ainda que não se manifeste exclusivamente de forma mercantil" (1996, p. 78). Por outro lado, para as pessoas comuns que habitam o campo e a cidade, a competitividade e a fluidez em escala mundial só existem como fábula.

Nos espaços opacos, onde vivem os "homens lentos", a fluidez e mobilidade acelerada encontram diversos empecilhos e obstáculos. A lentidão dos sujeitos, que pode parecer uma fraqueza no entendimento dos atores hegemônicos, é entendida pelo autor como sua força. Desta forma,

\begin{abstract}
quem, na cidade, tem mobilidade- e pode percorrê-la e esquadrinhá-la- acaba por ver pouco da Cidade e do Mundo. Sua comunhão com imagens, frequentemente pré-fabricadas, é a sua perdição. Seu conforto, que não desejam perder, vem exatamente do convívio com estas imagens. Os homens "lentos", por seu turno, para quem essas imagens são miragens, não podem, por muito tempo, estar em fase com este imaginário perverso e acabam descobrindo as fabulações. A lentidão dos corpos contrastaria então com a celeridade dos espíritos? (SANTOS, 1996, p. 84).
\end{abstract}

Entre estas fabulações, está o imperativo da competitividade. Há cotidianamente uma política dos de baixo (Santos, 2000) pautada na necessidade de continuar existindo e fortemente relacionada à solidariedade e cooperação. Este aspecto do cotidiano, é muito mais difícil de ser identificado à distância e fortemente calcado na espontaneidade e voltado para a manutenção da vida. Neste sentido, para os pobres

Na briga cotidiana pela sobrevivência, não há negociação possível para eles, e, individualmente, não há força de negociação. A sobrevivência só é assegurada porque as experiências imperativamente se renovam. E como a surpresa se dá na rotina, a riqueza dos "não-possuidores" é a prontidão dos sentidos. É com esta força que eles se eximem da contrafinalidade e ao lado da busca de bens materiais finitos cultivam a procura de bens infinitos como a solidariedade e a liberdade: estes, quanto mais se distribuem, mais aumentam (2000, p.130).

No contexto da atual pandemia da Covid-19, vemos emergir ambos aspectos, a competitividade e a cooperação, porém se apresentando mais evidentemente em contextos bem distintos. No contexto internacional e do mercado mundial, por exemplo, identificamos disputas por equipamentos de proteção individual e respiradores ${ }^{16}$. Disputas entre Estados e empresas pelo domínio de itens fundamentais para a 
manutenção da vida não parecem novidade. Assim como, no contexto dos pobres urbanos, dos "não-possuidores", dos homens lentos, o apoio mútuo em contextos de extrema dificuldade também são parte da luta pela vida que se reafirmam no atual contexto.

Diversos são os exemplos de ações de solidariedade através de doações e compartilhamento de itens, bem como exemplos de auto-organizações coletivas para a autoproteção e autocuidado. Optamos aqui por destacar, a título de exemplo, dois casos. O primeiro se refere a Paraisópolis, na Zona Leste de São Paulo, em que lideranças da comunidade organizaram "presidentes de rua" para monitorarem situações de saúde e necessidades emergenciais e campanhas de apoio a diaristas e pessoas desempregadas ${ }^{17}$. Outro exemplo são os diversos povos indígenas que, por conta própria, começaram a organizar formas de proteção e bloqueio de aldeias e Terras Indígenas, tanto no Brasil como em outros lugares da América Latina ${ }^{18}$.

Buscamos, assim, valorizar estas ações que podem parecer pequenas e espontâneas, no sentido de "desencantar acordos tácitos" (Ribeiro, 2011, p. 21) que banalizam a violência e a competitividade como elementos centrais na vida humana. As ações sociais, que tem em si a potência de descobrir "o que ainda não existe" (2011, p.24) são multiescalares e, por vezes, desafiam as estruturas de poder. Fundamental destacarmos como potentes estas ações coletivas e cooperativas, fundamentais na luta pela vida. Ainda como aponta Ribeiro:

mais do que nunca, faz-se necessária uma episteme dialógica, efetivamente democrática, que se comprometa com todos os outros, os muitos outros. Assim, será possível contrariar a ação que acontece "de cima pra baixo" com representações da experiência social baseadas em apreensões horizontais (e cooperativas) da vida coletiva (2011, p. 32).

Neste sentido, de propor um olhar geográfico atento tanto à ação do Estado, quanto às vulnerabilidades sociais e à força de resistência destes grupos, é que apontamos aqui estas possibilidades de reflexão, retornando às nossas referências formativas para imaginar possibilidades de futuro.

\section{Considerações Finais}

No acima exposto foi possível constatar que o trabalho intelectual da Geografia, no diálogo com outras ciências, é fundamental, contribuindo a análise do território na atual da crise da saúde para revelar as falhas e fragilidades do modelo neoliberal, o qual desenvolve formas de produção e de organização social que produzem riquezas para serem apropriadas por minorias, situação que vem se agravando no espaço e no tempo, promovendo efeitos devastadores no âmbito da crise da pandemia. Como afirma o expresidente do Uruguai José Mujica, “o capitalismo é a afirmação do indivíduo, e não da sociedade" (2020).

O quadro da saúde se agrava num país como o Brasil, principalmente na atual conjuntura político-econômica, sob a égide do autoritarismo, da insegurança e da violência, o qual ocupa posição de $6^{\circ}$ país mais desigual no ranking da desigualdade social no panorama internacional, apesar de ser um dos maiores produtores de alimentos do mundo, concentrando $50 \%$ da riqueza nas mãos de 100 pessoas. 
Quando indagamos sobre a existência desta desigualdade, desta miséria, estamos percebendo o território para a ação política. Uma leitura que deve orientar nossa visão política é o reconhecimento de que nem todos somos iguais e nem todos os espaços, e que também não percebemos a capacidade das pessoas de criar novas formas de vida porque não absorvemos o outro na sua própria força; nesse sentido, acabamos por reproduzir o olhar dominante (RIBEIRO, 2004).

\begin{abstract}
Em outras palavras, o território revela relação com concretude e alienação. Revela relação com concretude porque é a base do trabalho, da vida, das trocas, da identidade. Contudo, na medida em que o domínio contemporâneo é do dinheiro que produz dinheiro, isso produz alienação, fragmentação, falta de solidariedade. Mas o território tem uma força de desalienação desde que nossa leitura inclua os excluídos ou os precariamente incluídos, significando acionar o espaço do ponto de vista político. Encontrar o território da resistência passa pela leitura de outros discursos, diferentes do hegemônico, diferentes dessa lógica única que se impõe, discursos que proponham outras formas de vida, outras formas de cooperação, que façam outras leituras dos recursos do espaço, e é nesse sentido que o território é uma alternativa de politização (BERNARDES, 2011).
\end{abstract}

Fiori (2020) assevera que não é fácil perceber os grandes desafios e possíveis soluções, sugerindo a leitura do poema de Antonio Machado, que viveu durante a guerra civil espanhola, e que escreveu, "Caminante no hay camino, se hace el camino al andar". Ou seja, ao percebermos o território como recurso, não para a acumulação, mas para a vida, já estamos caminhando e, mais do que nunca, nesta crise é indispensável pensarmos juntos as novas tarefas que se colocam.

\title{
Notas
}

1 - SANTOS, Milton. As cidadanias mutiladas. In: O Preconceito, Julio Lerner Editor, São Paulo, 1996/1997.

2 - Letra da música "Dia de Graça", compositor de Candeia, 1970.

3 - Ver "População negra e Covid-19: desigualdades sociais e raciais ainda mais expostas".Disponível em: $\quad$ https://www.abrasco.org.br/site/outras-noticias/sistemas-de-saude/populacao-negra-e-covid-19desigualdades-sociais-e-raciais-ainda-mais-expostas/46338/. Acessado em: 19 abr. 2020

4 - Ver: "Diário Oficial da União". Disponível em: http://www.in.gov.br/en/web/dou/-/resolucao-n-11-de26-de-marco-de-2020-249996300. Acessado em 19 abr. 2019.

5 - Fundação criada estadunidenses em 1953 com o objetivo de levar o evangelho para povos ainda não alcançados pela palavra da bíblia. Ver mais em: https://www.novastribosdobrasil.org.br/historia . Acessado: 21 abr. 2020.

6 - Ver: "Em meio a pandemia, indígenas do Javari denunciam ameaça de missionários a isolados".Disponível em: https://www.socioambiental.org/pt-br/noticias-socioambientais/em-meio-apandemia-indigenas-do-javari-denunciam-ameaca-de-missionarios-a-isolados . Acessado em 20 abr. 2020.

7 - Ver "MPF pede investigação sobre demissão de diretor do Ibama após operação contra garimpo ilegal". Disponível em: https://oglobo.globo.com/brasil/mpf-pede-investigacao-sobre-demissao-dediretor-do-ibama-apos-operacao-contra-garimpo-ilegal-1-24374120. Acessado em 29 abr. 2020.

8 - Ver: "Projeto de Lei. Câmara dos Deputados". Disponível em: https://www.camara.leg.br/propostaslegislativas/2236765. Acessado em 22 abr. 2020.

9 - Ver: "Sonia Bone Guajajara, Ângela Kaxuyana e Dinaman Tuxá estão ao vivo".Disponível em: https://www.facebook.com/apiboficial/videos/1886062988192823/ . Acessado em 19 abr. 2020. 
10 - Ver "Funai aciona Força Nacional para evitar aglomerações frente ao novo coronavírus".Disponível em: $\quad$ http://www.funai.gov.br/index.php/comunicacao/noticias/5944-funai-aciona-forca-nacional-paraevitar-aglomeracoes-frente-ao-novo-coronavirus. Acessado em 22 abr. 2020.

11 - Ver: "Na prevenção ao coronavírus, Funai suspende autorizações de entrada em terras indígenas" Disponível em: http://www.funai.gov.br/index.php/comunicacao/noticias/5954-na-prevencao-aocoronavirus-funai-suspende-autorizacoes-de-entrada-em-terras-indigenas . Acessado em 22 abr. 2020.

12 - Ver: "Atendimento da FCP durante controle do COVID-19". Disponível em: http://www.palmares.gov.br/?p=55822. Acessado em 22 abr. 2020.

13 - Ver: "Palmares articula ações para proteger quilombolas da COVID-19". Disponível em: http://www.palmares.gov.br/?p=55865. Acessado em 22 abr. 2020.

14 - SESAI (Secretaria Especial de Saúde Indígena).

Ver: "Falando sobre às necessidades urgentes que devem ser adotadas em articulação intergovernamental entre estados e governo federal e também interinstitucional". Disponível em: https://www.facebook.com/GuajajaraSonia/videos/1660792530725499/ . Acesso em: 22 abr. 2020.

15 - Informe sobre o fechamento dos Caracoles pelos Zapatistas no México, devido à Pandemia de Covid19. Escrito pelo Subcomandante Insurgente Moisés, no México em março de 2020. Disponível em: http://enlacezapatista.ezln.org.mx/2020/03/18/devido-ao-coronavirus-o-ezln-fecha-caracoles-e-pede-paranao-abandonar-as-lutas-atuais/. Acessado em 17 de abril de 2020.

16 - Ver, por exemplo, a notícia de 06 de abril de 2020: Mercado internacional tem disputa por máscaras, luvas e respiradores. Disponível em: https://g1.globo.com/jornalnacional/noticia/2020/04/06/mercado-internacional-tem-disputa-por-mascaras-luvas-e-respiradores.ghtml. Acessado em: 17 de abril de 2020.

17 - Ver: Paraisópolis monitora 21 mil casas com presidentes de rua e médico próprio... - Veja mais em https://noticias.uol.com.br/saude/ultimas-noticias/redacao/2020/04/15/paraisopolis-contra-covid-favelatem-presidentes-de-rua-e-sistema-de-saude.htm?cmpid=copiaecola. Ver também: Paraisópolis cria rede de solidariedade para conter danos do coronavirus. Disponível em:https://saude.estadao.com.br/noticias/geral,paraisopolis-cria-rede-de-solidariedade-para-conter-danosdo-coronavirus, 70003270413. Acessado em: 17 de abril de 2020.

18 - Ver: "Indígenas fecham estradas e expulsam garimpeiros contra coronavirus" Disponpível em: https://www.msn.com/pt-br/noticias/brasil/ind\%C3\%ADgenas-fecham-estradas-e-expulsam-garimpeiroscontra-coronav\%C3\%ADrus/ar-BB12a6kL?ocid=spartandhp. Acessado em 20 de abril de 2020. Ver também: "Contra coronavírus, indígenas na Colômbia traçam plano radical". Disponível em: https://noticias.r7.com/internacional/contra-coronavirus-indigenas-na-colombia-tracam-plano-radical$\underline{05042020}$

\section{Bibliografia}

BARBOSA, Jorge Luiz. Por uma quarentena de direitos para as favelas e as periferias! In: Espaço e Economia Revista Brasileira de Geografia Econômica. Ano 9, n ${ }^{\circ}$, abril de 2020.

BERNARDES, Júlia Adão. "Novas fronteiras do capital no cerrado: cadeia carne/grãos". Conferência realizada na $63^{\mathrm{a}}$ Reunião Anual da SBPC intitulada Cerrado: água, alimento e energia. Goiânia, 2011.

BERNARDES, Júlia Adão. Novas fronteiras do capital no cerrado: dinâmica e contradições da expansão do agronegócio na região Centro-Oeste, Brasil. In: Scritpta Nova, Barcelona, 2016.

CAMPOS, Andrelino de Oliveira. Do quilombo à favela: a produção do "espaço criminalizado" no Rio de Janeiro. Rio de Janeiro: Bertrand, 2011.

CASTRO, Josué. Geografia da fome: o dilema brasileiro: pão ou aço. $10^{a}$ ed. Rio de Janeiro: Antares, 1984.

FIORI, José Luís. Prognóstico é ruim e vai piorar, diz Fiori. Tutameia: entreversos e desenredos [online]. 08 abr. 2020. Entrevista a Eleonora de Lucena e Rodolfo Lucena. Disponível em: < https://tutameia.jor.br/prognostico-e-ruim-e-vai-piorar-diz-fiori/ >. Acessado em 20 abr. 2020. 
HARVEY, David. Política anticapitalista em tempos de Covid-19: coronavírus e a luta de classes. In: DAVIS, Mike. et al (orgs.). Coronavírus e a luta de classes. Brasil: Terra sem Amos, 2020.

KROPOTKIN, Piotr. Ajuda mútua: um fator de evolução. São Sebastião: A Senhora Editora, 2009.

MARTINS, José de Souza. Na fila de espera. Revista IHU ON-Line [online], São Leopoldo, 18 abr. 2020. Entrevista ao Instituto Humanitas Unisinos. Disponível em: < http://www.ihu.unisinos.br/78-noticias/598154-na-fila-de-espera-artigo-de-jose-desouza-martins >. Acessado em: 21 abr. 2020.

MUJICA, José. Capitalismo, a afirmação de sociedade. Revista Exame [online], 09 abr. 2020. Disponível em: <https://exame.abril.com.br/revista-exame/capitalismo-a-afirmacao-dasociedade/ >. Acessado em: 21 abr. 2020.

PASTORAIS SOCIAIS DO CAMPO. Nota das Pastorais do Campo - Em defesa da vida e na construção permanente da esperança em tempos de covid-19. Conselho Indigenista Missionário [online], Brasil, 23 abr. 2020. Notícias. Disponível em: <https://cimi.org.br/2020/04/nota-das-pastorais-sociais-do-campo/>. Acessado em 23 abr. 2020.

RIBEIRO, Ana Clara Torres. Apontamentos das aulas do curso "Teorias da Ação", ministrado no IPPUR/UFRJ, 2004.

Territórios da sociedade: por uma cartografia da ação. In: Silva, Cátia Antonia.

Território e ação social: sentidos da apropriação urbana. Rio de Janeiro: Lamparina, 2011.

RIBEIRO, Letícia Parente. Evolucionismo, Darwinismo e neo-Lamarckismo: Matrizes do Pensamento Geográfico. In: Anais I Encontro Nacional de História do Pensamento Geográfico. Rio Claro: UNESP, 1999. v. 3.

SANTOS, Boaventura de Sousa. "A cruel pedagogia do vírus". In: Edições Almedina, S.A.Coimbra, 2020.

SANTOS, Milton. A natureza do espaço. São Paulo: Hucitec, 1996. . Técnica, espaço e tempo. São Pulo: Hucitec, 1996. As cidadanias mutiladas. In: O Preconceito, Julio Lerner Editor, São Paulo, 1996/1997. A escassez como motor da História. Jornal do Brasil. 24 set. 1997. Entrevista a Cláudio Cordovil, 1997.

. O dinheiro e o território. In: GEOgraphia. Ano. 1, n 1. Niterói, 1999.

Por uma outra globalização: do pensamento único à consciência universal. $4^{\mathrm{a}}$ ed. Rio de Janeiro: Record, 2000. . Espaço dividido. $2^{\mathrm{a}}$ ed. São Paulo: EdUSP, 2008.

SOUBEYRAN, OLIVIER. Darwin y Kropotkin: dos concepciones opuestas del progreso y sus implicaciones en Geografía humana. Revista de geografia, v. 18, n. 1, p. 31-46, 1984.

SOUZA, Maria Adélia A. de. Geografias da desigualdade: globalização e fragmentação. In: SANTOS, Milton; SOUZA, Maria Adélia A.; SILVEIRA, Maria Laura (Orgs.). Território: globalização e fragmentação.4ª ed. São Paulo: Hucitec, 1998.

WEBER, Max. Economía y sociedad. México: Fondo de Cultura, 1997. 